\title{
信夫山の斜面耕作
}

\section{〔安 田初旅〕}

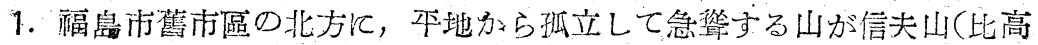

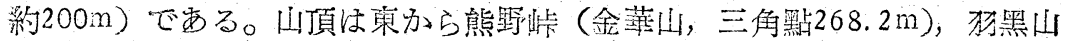

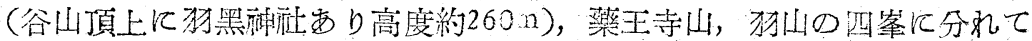

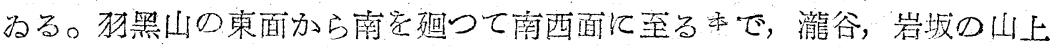

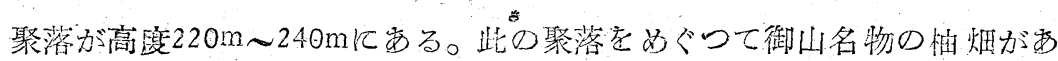

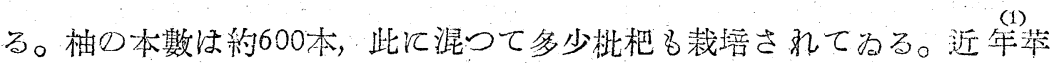

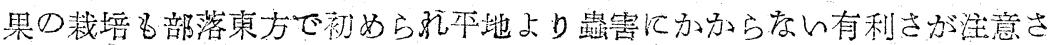

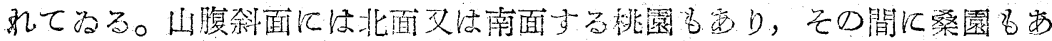
つて，此の山地の耕作景を特色づけてねる。柚の截唔は何時から初められ

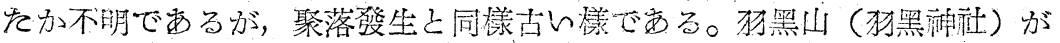

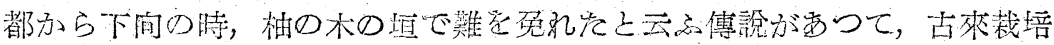

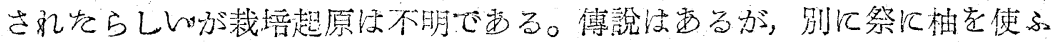

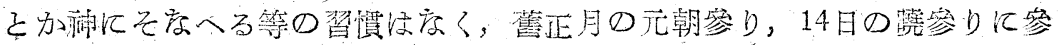

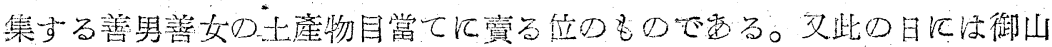

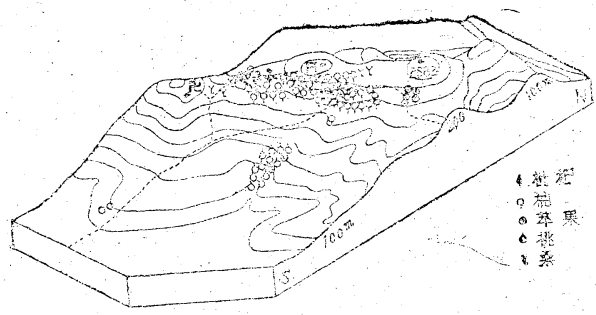

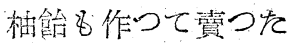
之云ぷ。德川時代の 記錄には柏につんて 法何口記事长巵ん が，培されなかつた 證にはならない。信 
(3)

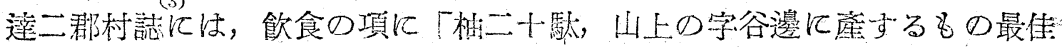

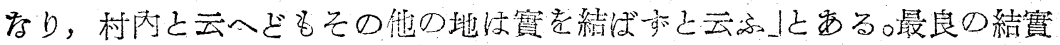

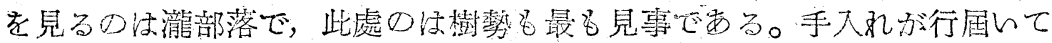

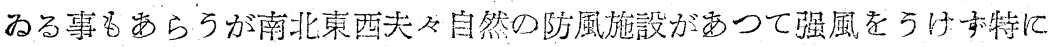
暖んとも考へられる。此に比して岩圾部落のもの将西及南風にさらされ，

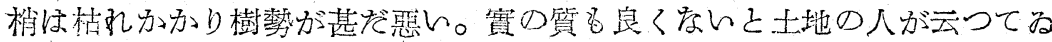

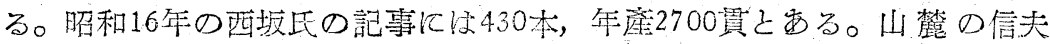
山㕕園內に一本柚があつて結䨳はするる゙，山上のもの程にはよくない。姿

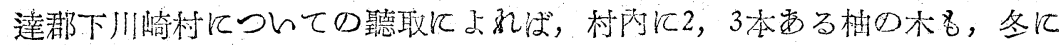

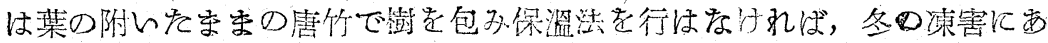

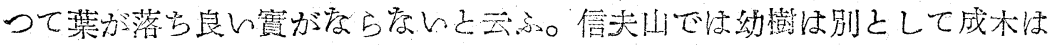

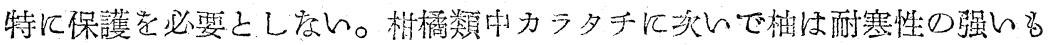

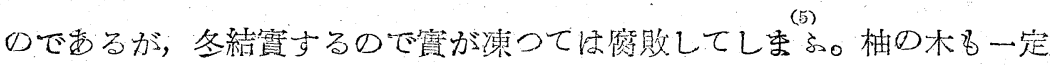

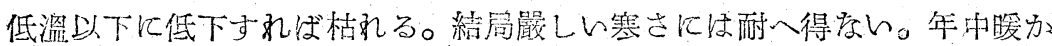

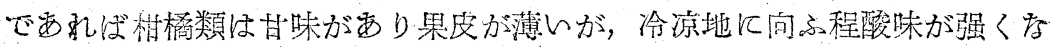

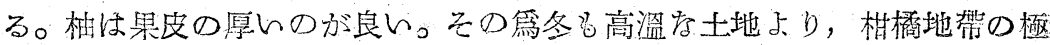
限界に近以位置で良果が得られる。

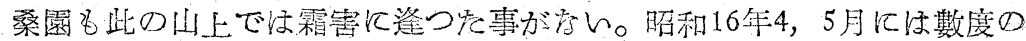

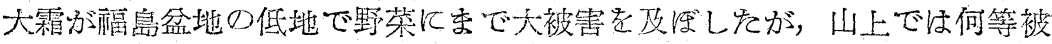

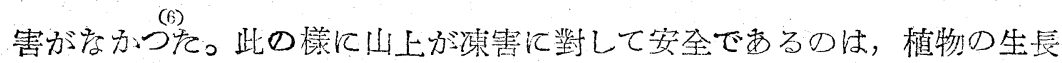
䦎始期が低地に比し晚んてと，寒され對する抵抗が低地の植物より大で交 ると考へられるとと等もあるが，科溫の逆輽が最も重要存原因であらら。

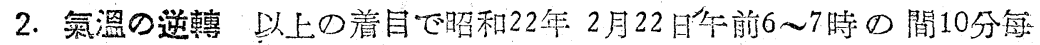
に山上から中腹山麓各部12ケ所だ氣温の觀測を實施した。なるべく晴れを 


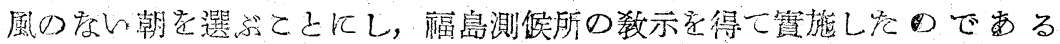

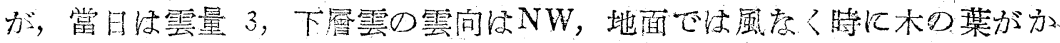

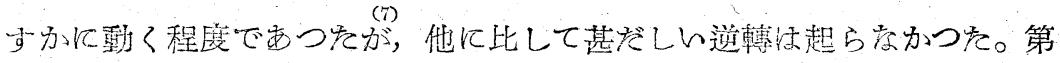
2圆け 6時20分の爿態を示す。中腹部が高溫で上部々平地とD氣溫差より

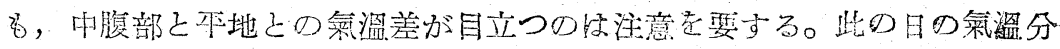
布に關して々别報告したん。

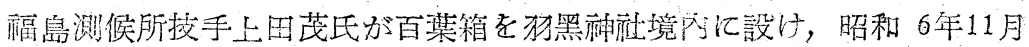

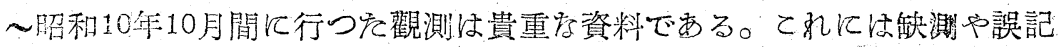
が放り，测候所の資料程確珼性はをんが，今のさころ信夫山に關する限り

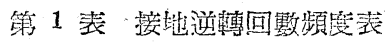

\begin{tabular}{|c|c|c|c|c|c|c|c|c|c|c|c|c|c|}
\hline 月 & 1 & 2 & 3 & 4 & 5 & 6 & 7 & 8 & 9 & 10 & 11 & 12 & 計 \\
\hline A & 87 & 77 & 81 & 75 & 87 & 89 & 81 & 73 & 92 & 53 & 76 & 89 & 960 \\
\hline$\eta$ & 0 & 0 & 0 & 1 & 0 & 0 & 1 & 0 & 0 & 1 & 1 & 0 & 4 \\
\hline$Y$ & 0 & 1 & 0 & 2 & 0 & 0 & 0 & 0 & 0 & 1 & 1 & 3 & 8 \\
\hline $\mathrm{W}$ & 4 & 1 & 2 & 4 & 2 & 0 & 0 & 0 & 1 & 1 & 5 & 3 & 23 \\
\hline II & 4 & 5 & 0 & 6 & 4 & 5 & 0 & 1 & 4 & 10 & 8 & 9 & 56 \\
\hline II & 14 & 16 & 9 & 9 & 9 & 10 & 4 & 5 & 8 & 6 & 10 & 20 & 126 \\
\hline$y$ & 14 & 11 & 9 & 10 & 13 & 8 & 17 & 8 & 12 & 8 & 11 & 7 & 128 \\
\hline 部 & 36 & 34 & 20 & 32 & 28 & .23 & 22 & 14 & 25 & 27 & 42 & 42 & 345 \\
\hline$\%$ & 41.3 & 44.1 & 24.7 & 42.6 & 32.1 & 24.4 & 27.0 & 19.1 & 27.0 & 50.9 & 55.2 & 47.1 & 35.9 \\
\hline 默 & 70 & 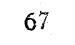 & 35 & 78 & 51 & 43 & 31 & 21 & 44 & 65 & 98 & 101 & \\
\hline$\%$ & 80.4 & 87.0 & 43.2 & 104.0 & 58.6 & 48.0 & 38.0 & 28.7 & 47.7 & 122.6 & 128.9 & 113.4 & \\
\hline
\end{tabular}

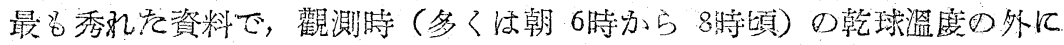
最高最低菓溫が記載されてある。乙れを利用して次の如く整理して見た。

(1) 同一日の福島測候所氏於ける最低氣溫と比較し，山上の最侻舞溫が 高い示度定示寸日數を月別に計數した。

(2) その場合の示度の差を0. $1^{\circ} \sim 1.0^{\circ} \mathrm{C}, 1.0^{\circ} \sim 1.9^{\circ} \mathrm{C}, 2.0^{\circ} \sim 2.9^{\circ} \mathrm{C}$, 
80

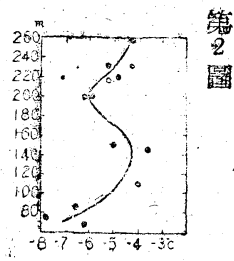

第3圆
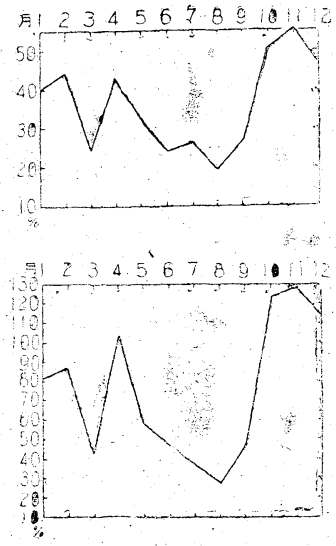

が大をんの注目に倠する。此の期に屡ふ山上の最低莍溫が山下よりも高 レのでする。

最低氣溫の起時は山上と山下で多少時刻に喰ひ違ひがある筈でする。自

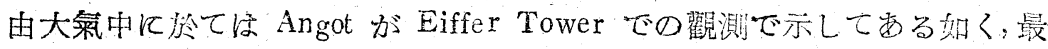

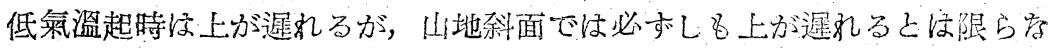
レ。昭和 22 年 2 月 22 日狗黑山での觀測では，中腹及び頂上が山柧に比して

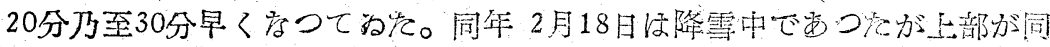

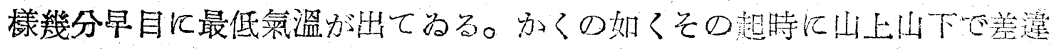

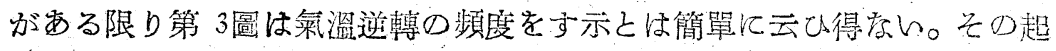

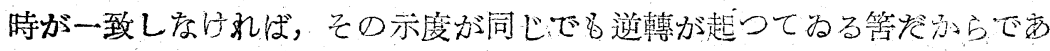
る。又山上が仙下より高い示度を示すをらその差以上の氣溫差の逆轉が起 
つてぬる事になる。この上下二點で注把握不可能な逆轉名との中間で起り

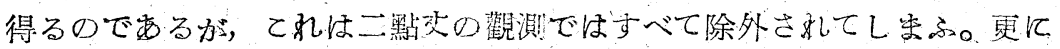

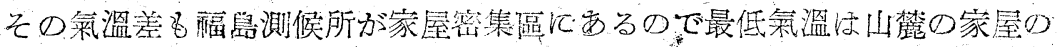

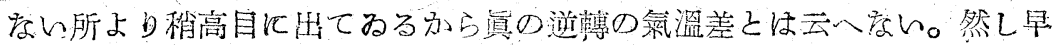

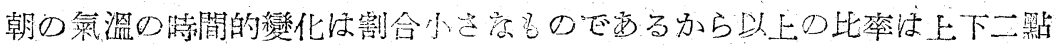

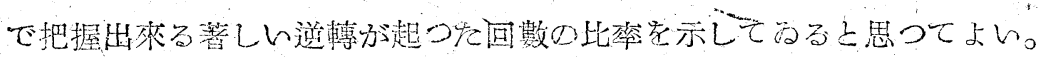

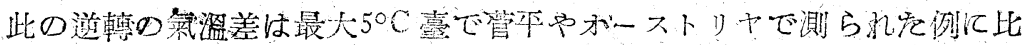
(9)

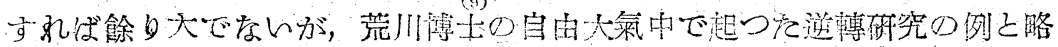
似在結果が出て为る。

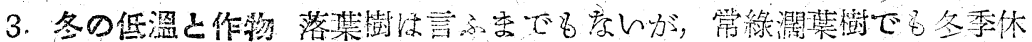

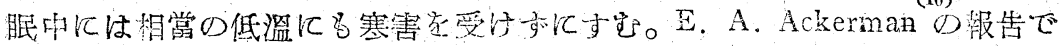

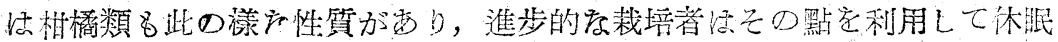

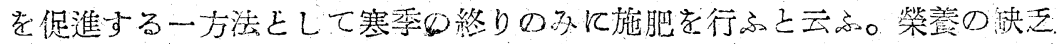

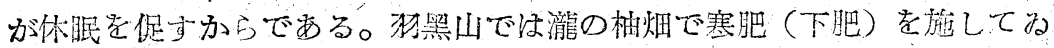

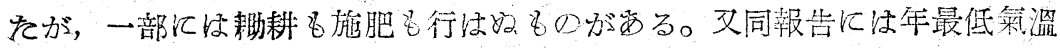

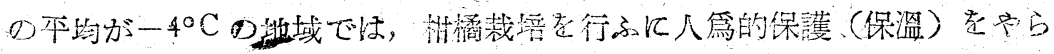

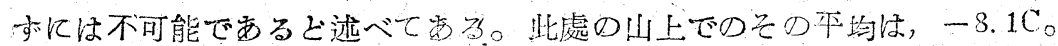

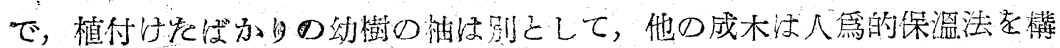

第 2 洼

\begin{tabular}{|c|c|c|}
\hline 年度 & 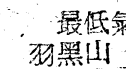 & 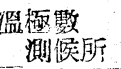 \\
\hline 昭和 7 " & $-8.80 \mathrm{C}$ & $-9.9^{\circ} \mathrm{C}$ \\
\hline 118 & $-9.5 \prime \prime$ & $-10.4 \prime \prime$ \\
\hline 119 & $-7.2 "$ & $-8.5 \mu$ \\
\hline " 10 & $-7.0 \prime \prime$ & $-9.7 " 1$ \\
\hline 平妁 & $-8.1^{\circ} \mathrm{C}$ & $-0.6^{\circ} \mathrm{C}$ \\
\hline
\end{tabular}

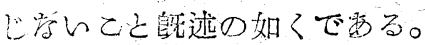

柚畑は海拔210〜250m 闆に存在し；犲黑山

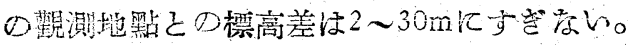
かくて怞がモれれ低溫に耐へ得るか目下資 料を手にしてみ存んが，此の程度の低溫存ら

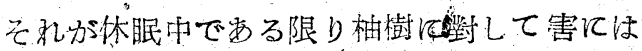


疗方疗的。

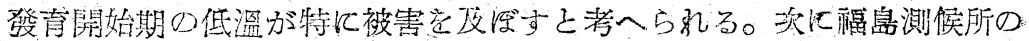

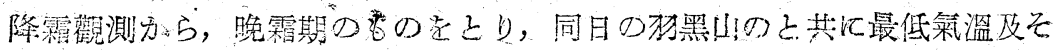

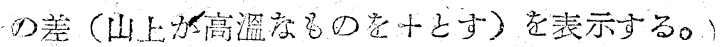

\section{第 3 袁}

\begin{tabular}{|c|c|c|c|c|}
\hline 年 & 月 日 & 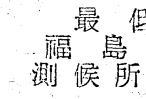 & 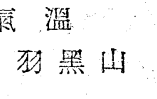 & 造 \\
\hline 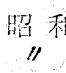 & $\begin{array}{l}7,4,7 \\
\text { i/ } 4,20\end{array}$ & $\begin{array}{c}-2.0^{\circ} \mathrm{C} \\
0.8\end{array}$ & $\begin{array}{c}0.5 \mathrm{C} \\
\quad 2.0\end{array}$ & $\begin{array}{l}+1.5 \\
+1.2\end{array}$ \\
\hline "I & $\begin{array}{l}8,4,-17 \\
44,18 \\
12,7,7\end{array}$ & $\begin{array}{r}-1.8 \\
1.6 \\
1.5\end{array}$ & $\begin{array}{l}0.6 \% \\
4.2 \%\end{array}$ & $\begin{array}{l}+2.4 \\
+2.7\end{array}$ \\
\hline $\begin{array}{l}11: \\
11 \\
11 \\
11\end{array}$ & 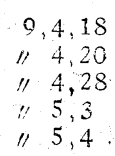 & $\begin{array}{r}-1.0 \\
1.5 \\
1.3 \\
-0.9 \\
1.0\end{array}$ & $\begin{array}{l}2.3 \% \\
5.1 \% \\
3.2 \% \\
2.0 \% \\
3.0 \%\end{array}$ & $\begin{array}{l}+3.3 \\
+3.6 \\
+1.9 \\
+2.9 \\
+2.0\end{array}$ \\
\hline "I & $\begin{array}{c}10,4,13 \\
\prime \prime 4,18 \\
\text { II } 5,4\end{array}$ & $\begin{array}{r}-2.8 \\
1.8 \\
1.5\end{array}$ & $\begin{array}{r}-0.3 \\
1.5 \%(1) \\
4.8\end{array}$ & $\begin{array}{r}+2.5 \\
-0.3 \\
+3.3\end{array}$ \\
\hline
\end{tabular}

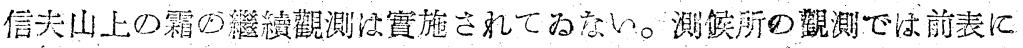

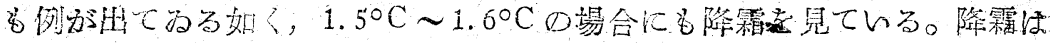

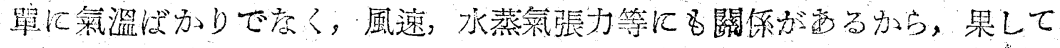

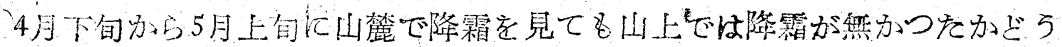

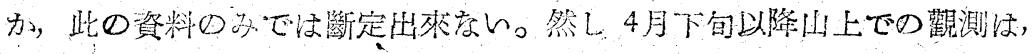

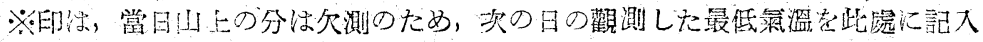

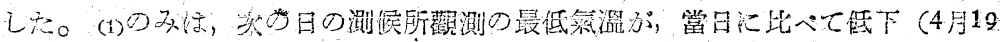

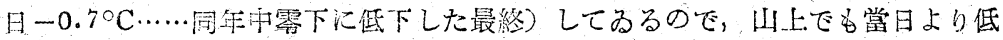

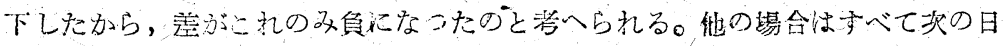

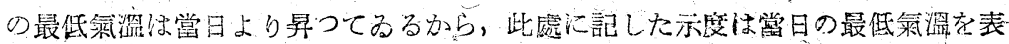
は生公賞施太た要る。 


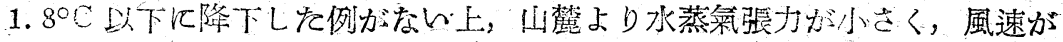

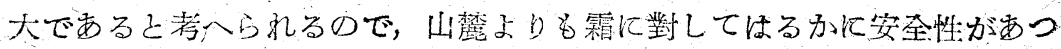

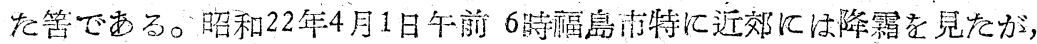

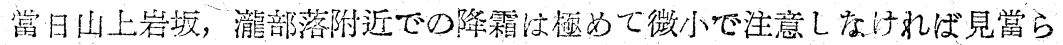

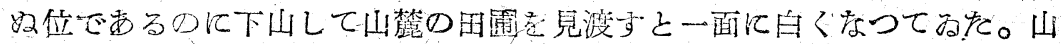

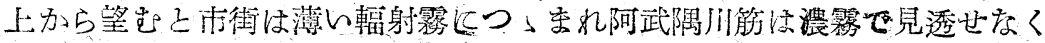

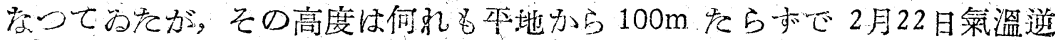

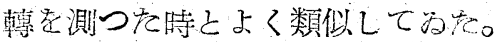

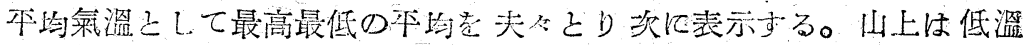
一第 4 表

\begin{tabular}{|c|c|c|c|c|c|c|c|}
\hline 月 & 1 & 2 & 3 & 4 & 5 & 6 & 7 \\
\hline 雅黑 Uf $(260 \mathrm{~m})$ & -0.12 & 0.55 & 2.79 & 9.07 & 15.21 & 19.13 & 322.50 \\
\hline 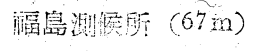 & 0.55 & 1.15 & 4.15 & 10.70 & 15.30 & 19.75 & $5 \quad 23.90$ \\
\hline 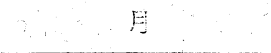 & 8 & 9 & 10 & 11 & 12 & 等 & 埆 考 \\
\hline 㭁黑 U (260m) & 23.75 & 19.26 & 11.91 & 7.06 & 2.76 & 11.15 & 4万年平均 \\
\hline 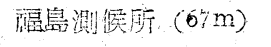 & 25.15 & 20.80 & 14.15 & 8,30 & 3.10 & 12.20 & 羅年平均 \\
\hline
\end{tabular}

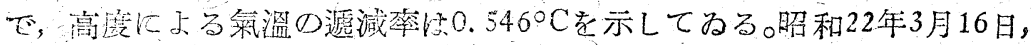

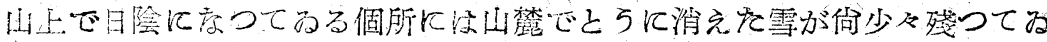

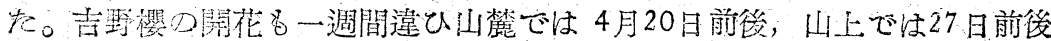

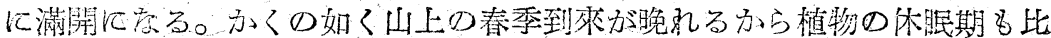

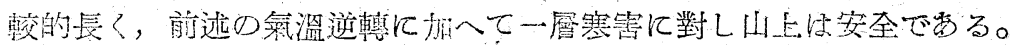

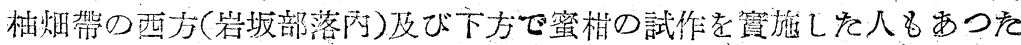

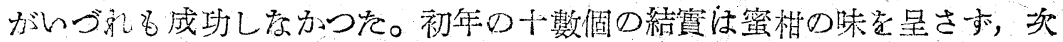

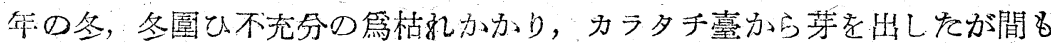

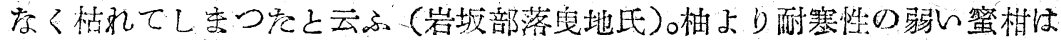


此處の寒さには耐入得ない。

此處の斜面で注120〜130m估の高度には新しい集嘈的存枇杷園が設けら れてるる。柚畑帶との比較る自下資料がをい。柚畑帶をどの程度下方迄下

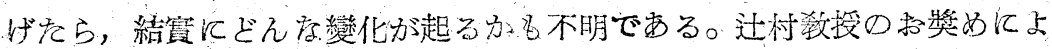
b第一報上して御高評定仰ぐ次第で西る。

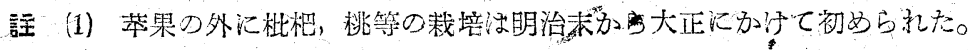

(2) 西战茂 信未昭昭和16年

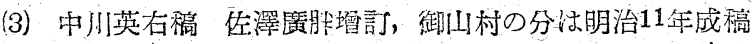

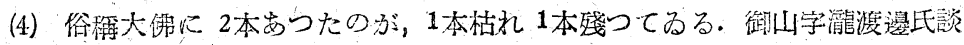

(5) E.A.Ackerman;Influences of Climate on the Cultivation of Citrus, (Geogr.Rev, 1938, p. 289) Кよるとオレンヂ類の筫はー $-2.2^{\circ} \sim 2.7^{\circ} \mathrm{C}$ ，

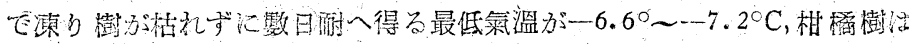

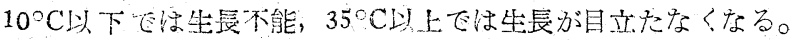

(6) 西坂茂 前楊

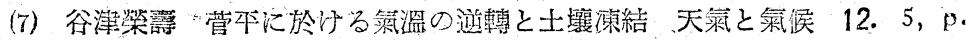
14. 福井英一郎 州候學 P. 260 。

(8) Tarr; College phisiography, 1914 p. 730

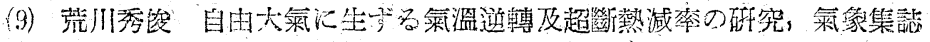
14. 6 ,

(10) E.A.Ackerman，前揭 (昭稩22年4月21日受理) 